
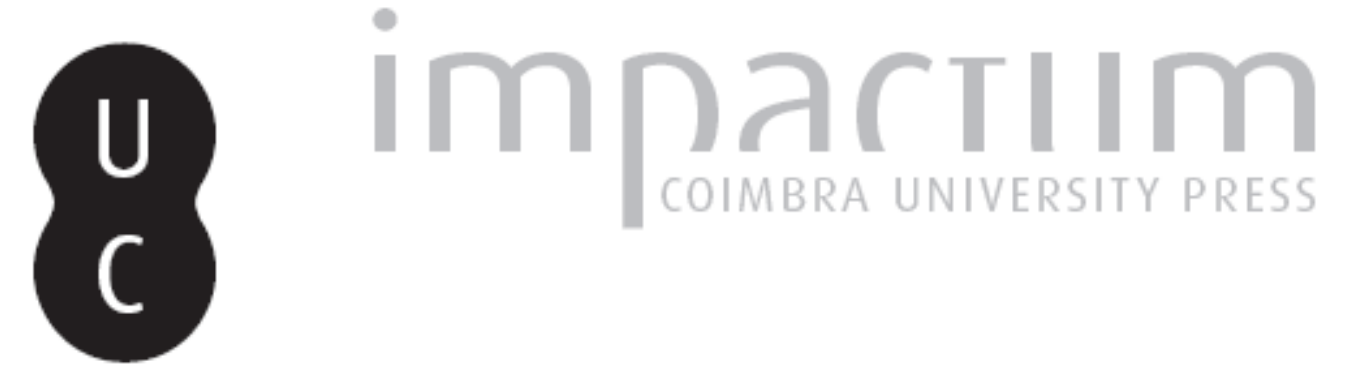

\title{
Análise crítica da directiva dos direitos dos consumidores e da sua transposição
}

Autor(es): $\quad$ Frade, Catarina; Almeida, Mariana Pinheiro de

Publicado por: Centro de Informação Europe Direct de Aveiro; Centro de Estudos Interdisciplinares do Século XX

URL

persistente:

URI:http://hdl.handle.net/10316.2/33985

DOI:

DOI:http://dx.doi.org/10.14195/1647-6336_11_14

Accessed : $\quad$ 26-Apr-2023 14:27:52

A navegação consulta e descarregamento dos títulos inseridos nas Bibliotecas Digitais UC Digitalis, UC Pombalina e UC Impactum, pressupõem a aceitação plena e sem reservas dos Termos e Condições de Uso destas Bibliotecas Digitais, disponíveis em https://digitalis.uc.pt/pt-pt/termos.

Conforme exposto nos referidos Termos e Condições de Uso, o descarregamento de títulos de acesso restrito requer uma licença válida de autorização devendo o utilizador aceder ao(s) documento(s) a partir de um endereço de IP da instituição detentora da supramencionada licença.

Ao utilizador é apenas permitido o descarregamento para uso pessoal, pelo que o emprego do(s) título(s) descarregado(s) para outro fim, designadamente comercial, carece de autorização do respetivo autor ou editor da obra.

Na medida em que todas as obras da UC Digitalis se encontram protegidas pelo Código do Direito de Autor e Direitos Conexos e demais legislação aplicável, toda a cópia, parcial ou total, deste documento, nos casos em que é legalmente admitida, deverá conter ou fazer-se acompanhar por este aviso.

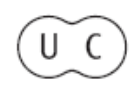


DEBATER

A EUROPA

jul-dez 2014

QUE EUROPA(S)?

CONTEXTOS E DESAFIOS 


\title{
Análise crítica da directiva dos direitos dos consumidores e da sua transposição
}

\author{
Catarina Frade \\ Docente da Faculdade de Economia da UC \\ Investigadora CES-UC \\ E-mail: cfrade@fe.uc.pt \\ Mariana Pinheiro de Almeida \\ Docente do Instituto politécnico do Cávado e Ave \\ Doutoranda da FDUC/FEUC \\ E-mail: mariana.pinheiro.almeida@gmail.com
}

\section{Resumo}

A directiva europeia de 2011 relativa aos direitos dos consumidores, transposta em 2014 para o direito português, está em sintonia com a alteração que desde os anos 2000 se observa no direito e na política dos consumidores na UE: a de uma abordagem mais liberal da defesa dos consumidores que a torna, por isso, mais instrumental em relação ao objectivo último da construção do mercado interno. A opção pela harmonização total em desfavor da harmonização mínima que predominou no passado e o reforço da aposta na informação tout court deixam perceber como as questões dos consumidores estão hoje mais vulneráveis a uma regulação dita "por baixo".

Palavras-chave: direitos dos consumidores; directiva, harmonização; transposição

\begin{abstract}
The European directive on consumer rights of 2011, transposed in 2014 to the Portuguese legal order, is in line with the more liberal approach to EU consumer law and policy observed since the years 2000s. Consumer protection at EU level became therefore more instrumental in relation to the ultimate objective of the construction of the internal market. Opting for the full harmonization in detriment of minimum
\end{abstract}


harmonization that prevailed in the past and showing greater commitment to disclosure, EU approach allow us to understand how consumer issues are now more vulnerable to lower levels of legal protection.

Keywords: consumer rights; Directive, harmonization; transposition

\section{Introdução}

A protecção dos consumidores foi acolhida progressivamente na ordem jurídica europeia especialmente a partir dos anos 80 do século $\mathrm{XX}$, mas a sua afirmação mais forte teve lugar nos anos seguintes, mercê do seu reconhecimento como política comum em 1992, com o Tratado da União Europeia.

A partir dos anos 2000, contudo, observa-se uma alteração desse reconhecimento político e da sua força jurídica, quando o executivo comunitário passou a passou a adoptar uma posição mais liberal da defesa dos consumidores, alicerçada numa concepção de um consumidor médio, avisado e racional, que é capaz de efectuar escolhas ajustadas para as quais era importante salvaguardar a necessária informação.

A aposta no dever de informação torna-se particularmente saliente e representa uma transferência da responsabilidade e do risco contratual do vendedor e do Estado, para o comprador. Paralelamente a Comissão Europeia iniciou um amplo movimento de revisão do acervo comunitário relativo á defesa do consumidor, adoptando uma nova lógica reguladora: a da harmonização máxima ou total do quadro regulatório europeu.

Estas tendências registadas na política e no direito europeu dos consumidores podem ser comprovadas no processo conducente à aprovação, em 2011, da nova directiva relativa aos direitos dos consumidores - Directiva 2011/83/UE do Parlamento Europeu e do Conselho, de 25 de Outubro de 2011. Depois de um texto inicial em que a Comissão Europeia sufragava a harmonização total, substituindo assim a lógica de harmonização mínima que fora consagrada na directiva de 1985 (Directiva 85/577/CEE do Conselho, de 20 de Dezembro de 1985), viria a ser adoptada uma solução de compromisso. Porém, trata-se de um compromisso manifestamente escasso.

O presente texto pretende dar conta desses aspectos aqui referidos e também mostrar de que modo o legislador português, imerso neste contexto, procedeu à transposição da referida directiva para a ordem jurídica interna. 


\section{A adopção da directiva dos direitos dos consumidores em contexto de} descompasso institucional

Com a aprovação do texto final da Directiva 2011/83/UE do Parlamento Europeu e do Conselho, de 25 de Outubro de 2011, relativa aos direitos dos consumidores, foi dado mais um passo na consolidação de uma nova abordagem à protecção dos direitos e interesses dos consumidores europeus que se iniciou na década de 2000 e que introduz, no dizer de alguns autores, uma "abordagem liberal da protecção dos consumidores"1. Esta abordagem revelou-se nas iniciativas políticas e legislativas europeias neste domínio, designadamente no Livro Verde sobre a defesa dos consumidores na UE $(2001)^{2}$ e nas directivas e programas de acção quinquenais subsequentes.

Durante os anos 90 do século XX, a política do consumidor fora erigida em política comum de pleno direito através do Tratado da União Europeia (1992) (art. 129 -A e depois art. $153^{\circ}$ do Tratado de Amesterdão de 1997 - actual art. $169^{\circ}$ TFUE). Nessa altura, os planos de acção trianuais e as iniciativas da Comissão Europeia através da nova comissária dos assuntos dos consumidores (Emma Bonino) tinham dado foros de cidadania aos consumidores, depois de nos períodos precedentes eles terem sido encarados apenas como agentes económicos cuja acção deve ser tomada em conta para garantir o bom funcionamento do mercado.

De algum modo esta ideia inicial foi retomada a partir de 2000, na medida em que a política dos consumidores foi colocada de forma ostensiva ao serviço do objectivo da realização do mercado interno. Esta subalternização das políticas sociais europeias, como a política de protecção dos consumidores, aos propósitos da afirmação do mercado interno constitui uma inflexão no reforço dos interesses não estritamente económicos e nas questões de cidadania que haviam sido introduzidos precisamente pelo Tratado da União Europeia.

Esta abordagem liberal da política e dos direitos dos consumidores, que é hoje visível sobretudo na acção da Comissão Europeia (ainda que ao nível do discurso esta

\footnotetext{
${ }^{1}$ Cfr. LIZ, Jorge Pegado (2011),Tendências Internacionais e Nacionais da Politica de Protecção dos Consumidores, Actas do I Congresso Internacional do Observare, UAL/FCG. O autor fala na "idade de bronze" da política e dos direitos dos consumidores, para sublinhar o retrocesso que, na sua perspectiva, se iniciou na política europeia do consumidor a partir de 2001. CSERES, Katia (2005),The interplay between consumer protection and competition law in the EC, Revue européenne de droit de la consommation,/European Journal of Consumer Law, 2.

${ }^{2} \mathrm{COM} / 2001 / 0531$ final, de 2.10.2001.
} 
apareça suavizada como se pode constatar no texto da Agenda do Consumidor Europeu, de $2012^{3}$ ), assenta em várias premissas e concretiza-se em diferentes procedimentos e metodologias.

Uma das premissas fundamentais neste domínio da defesa dos consumidores é a de que o consumidor-tipo é "atento e advertido" e alguém capaz de, uma vez dotado da necessária e adequada informação, tomar decisões correctas, consistentes e adequadas aos seus interesses. Ao paradigma inicial de um consumidor dotado de um menor poder negocial porque se encontra numa posição mais fraca em relação ao profissional com quem contrata, sucede o paradigma do "consumidor médio" capaz de ser responsável e responsabilizado pelas decisões que toma e pelos riscos que assume.

O desenvolvimento desta premissa efectua-se privilegiadamente através de dois instrumentos: o dever de informação e a harmonização máxima do quadro legal.

a) $\mathrm{O}$ dever de informação afirma-se como o principal instrumento ou método para assegurar a capacitação do consumidor (enforcement), aquele que, uma vez regularmente cumprido por parte do comerciante ou prestador de serviços permitirá uma escolha adequada e em condições de liberdade. Esta opção jurídica pelo reforço da informação ao consumidor é o corolário natural da ideologia económica dominante de cariz neoclássico e liberal. Segundo esta perspectiva, o consumidor é um ser racional que escolhe sempre o que maximiza a sua utilidade, o seu bem-estar, uma vez que seja dotado de informação completa e perfeita. Ora, já a própria teoria neoclássica reconhecia a falácia do pressuposto de racionalidade ilimitada e mais recentemente outras teorias como a economia comportamental, a sociologia económica e a psicologia económica têm demonstrado, socorrendo-se inclusive de estudos empíricos, que os indivíduos têm uma racionalidade limitada, que não conseguem digerir senão quantidades limitadas de informação, que têm dificuldade em fazer operações de grande complexidade e que são selectivos no tipo de informação que usam para tomar decisões ${ }^{4}$. Nessa medida, a aposta na informação, em mais informação, pode não produzir os resultados esperados de obter-se escolhas mais sustentáveis e decisões mais

\footnotetext{
${ }^{3}$ Comunicação da Comissão COM (2012) 225 final, de 22.5.2012.

${ }^{4}$ SANTOS, Ana Cordeiro; COSTA, Vânia (2013), Regular o consumidor? Novas tendências de política no setor financeiro, Análise Social, 209, XLVIII,4, 756-790; FRADE, Catarina (2007), A regulação do sobreendividamento. Dissertação de doutoramento. Coimbra: FEUC.
} 
adequadas. Aliás, a própria Comissão Europeia, ainda que de forma envergonhada, reconhece que maior informação não conduz necessariamente a mais conhecimento ${ }^{5}$.

Não obstante, a aposta na informação é sumamente atraente, nomeadamente para os poderes públicos:

- por um lado, transferem esse dever para os operadores económicos, estabelecendo-lhes standards e orientações para a sua provisão (fichas normalizadas, formulários electrónicos, conteúdos obrigatórios e prazos de comunicação) e alienando de si a maioria da responsabilidade;

- por outro, transformam o consumidor no "guarda de si mesmo e do mercado". Segundo a sua perspectiva, o consumidor informado é capaz de zelar pelos seus interesses económicos e reconhecer os seus limites e as suas vulnerabilidades. Os vícios da vontade podem, por isso ser-lhe imputados e os prejuízos correm por sua conta. A informação que é prestada ao consumidor aumentará a sua confiança no mercado e potenciará a expansão das transacções económicas, nomeadamente transfronteiriças. Como consta do próprio Programa "Consumidores" que integra o Orçamento da UE para 2014-2020, "consumidores confiantes ajudam a criar mercados prósperos".

Além do mais, o consumidor informado é também um agente bem situado no terreno para identificar e denunciar más práticas comerciais e os seus autores, poupando ao Estado os custos de uma acção fiscalizadora mais efectiva e actuante;

- finalmente, em tempos de crise, o reforço da informação constitui uma medida regulatória de baixo custo, com grande aceitabilidade social (mesmo que não haja estudos para avaliar os seus eventuais efeitos positivos), que pode compensar a falta de investimento regulatório em processos mais exigentes, onerosos e complexos, como iniciativas de fiscalização e sancionamento.

b) $\mathrm{O}$ segundo instrumento de promoção da referida premissa da abordagem liberal da política dos consumidores é, como se referiu, a preferência crescente pela harmonização máxima dos quadros legislativos nacionais. Antes de 2000, a protecção dos consumidores afirmou-se através da adopção de diversos actos jurídicos derivados, mormente de directivas, organizados em torno do princípio da harmonização mínima.

\footnotetext{
${ }^{5}$ Cf. Ponto 3.3 da Agenda do Consumidor Europeu, de 2012, cuja epigrafe é "Sobrecarga de informação - défice de conhecimentos". O título, contudo, sugere algo que depois o texto não concretiza plenamente: os limites do excesso de informação e as limitações que os indivíduos têm em processá-la.
} 
Deste modo, os Estados-Membros mantinham o poder de elevar o nível de protecção conferido aos consumidores pelos ordenamentos jurídicos nacionais ou manter o nível mais elevado que já possuíam.

De então para cá, a Comissão Europeia alterou a sua abordagem e avançou com propostas de directiva baseadas no pressuposto da harmonização total (sem, contudo, ter a coragem de optar pelo regulamento) ${ }^{6}$. É o caso das directivas sobre práticas comerciais desleais (Directiva 2005/29/CE do Parlamento Europeu e do Conselho, de 11 de Maio de 2005), sobre crédito ao consumo (Diretiva n. ${ }^{\circ}$ 2008/48/CE, do Parlamento Europeu e do Conselho, de 23 de abril, relativa a contratos de crédito aos consumidores, sobretudo na versão inicial apresentada em 2002) e sobre os direitos dos consumidores (Directiva 2011/83/UE do Parlamento Europeu e do Conselho, de 25 de Outubro de 2011, especialmente na versão inicial apresentada em 2008).

Esta mudança radical na metodologia e no alcance da intervenção legislativa europeia em matéria de protecção dos consumidores tem sido fonte de fricção entre o executivo comunitário e o Parlamento Europeu e os principais órgãos consultivos da UE (Comité Económico e Social Europeu e o Comité das Regiões), como demonstra o processo legislativo que culminou na adopção da já referida directiva de 2011 sobre os direitos dos consumidores e do qual daremos conta de seguida.

\section{Os termos iniciais da harmonização máxima na proposta de directiva relativa aos direitos dos consumidores (COM/2008/0614 final - COD 2008/0196)}

Num contexto de clara expansão e afirmação do Direito do Consumidor ${ }^{7}$, face ao incremento de complexas evoluções tecnológicas desencadeadas numa sociedade dominada por arreigados e intensos hábitos de consumo, urge a necessidade de aumentar o âmbito de protecção dos consumidores, sobretudo quando estes transacionam cada vez mais à distância ou fora do estabelecimento comercial.

A Directiva 85/577/CEE do Conselho, de 20 de Dezembro de 1985, relativa à protecção dos consumidores no caso de contratos negociados fora dos estabelecimentos

\footnotetext{
${ }^{6}$ CHIRITA, Anca Daniela (2012), The Impact of Directive 2011/83/EU on Consumer. Ius Commune Law Series, Intersentia.

${ }^{7}$ Calvão da Silva define-o como "uma consciência critica e consciência moral do Direito Civil que é a parte nevrálgica vivificadora, rejuvenescedora e eticizadora do Direito do homem comum e suposto contraente mais fraco, a caminho de um harmonizado direito privado europeu dos contratos (desejável) no mais vasto processo de internacionalização e globalização da economia e do comércio". Cf. CALVÃO DA SILVA, João (2010), Venda de Bens de Consumo, Revista Aumentada e Actualizada, $4^{a}$ ed, Coimbra: Almedina.
} 
comerciais e a Directiva 97/7/CE do Parlamento Europeu e do Conselho, de 20 de Maio de 1997, relativa à protecção dos consumidores em matéria de contratos à distância, haviam consagrado um determinado número de direitos contratuais dos consumidores. Contudo, como se disse, a alteração dos modelos de aquisição de bens e serviços, a desmaterialização das relações de compra e venda, e a reconfiguração do espaço e do tempo nas transações comerciais justificou a modernização daquele quadro normativo.

Nesse seguimento, surgiu em 2008 a Proposta de Directiva sobre os Direitos dos Consumidores $^{8}$ a qual pretendeu efectuar uma total revisão do direito do consumo, e de modo particular de quatro directivas. Além das já referidas Directivas 85/577/CE a directiva 97/7/CE3, foram ainda incluídas no pacote a Directiva 99/44/CEE sobre as garantias prestadas em vendas de bens de consumo e a Directiva 99/13/CE, relativa às cláusulas contratuais abusivas.

A proposta de 2008 aspirou à imposição de normas sistemáticas que permitissem uma tradução coerente e uniforme de todos os aspectos relacionados com aqueles diplomas, mediante a aplicação do princípio da harmonização máxima.

Assim, e na versão original da Proposta de Directiva sobre os direitos dos consumidores, $\mathrm{o}$ art. $4^{\mathrm{o}}$ consagrava que:

"os Estados Membros não podem manter ou introduzir na sua legislação nacional disposições contrárias as previstas na presente directiva, nomeadamente, disposições mais ou menos rigorosas, que tenham por objectivo garantir um nível de defesa dos consumidores diferente".

De acordo com o entendimento seguido pela proposta, urgia, assim, a imposição de uma harmonização total tendo em consideração as acentuadas diferenças legislativas, no que a esta matéria diz respeito, nos diferentes Estados-Membros. Segundo a Comissão, estas diferenças impediriam o desenvolvimento do mercado comum, criando barreiras tanto ao consumidor, como às empresas que poderiam ver-se limitadas a um determinado e específico tipo de consumidor. Em defesa desta tese, esgrimia-se o argumento de que, perante diferentes regulações do mesmo aspecto jurídico, os consumidores temiam celebrar contratos transfronteiriços, acomodando-se, por isso, aos contratos celebrados apenas no seu Estado-Membro 9 .

\footnotetext{
8 Proposta de Directiva do Parlamento Europeu e do Conselho sobre direitos dos consumidores COM/2008/0614 final - COD 2008/0196. Disponível em http://eur-lex.europa.eu/legalcontent/PT/TXT/PDF/?uri=CELEX:52008PC0614\&from=EN.

9 SMIT, Jan (2009), Full Harmonization of Consumer Law? A Critique of the Draft Directive on Consumer Rights, European Review of Private Law, volume.18. "They would experience that crossborder transactions are most costly than transactions within one's own country, and these high costs could
} 
O Considerando $8^{\circ}$ da Proposta previa também que,

"a harmonização total de alguns aspectos reguladores fundamentais permitirá aumentar consideravelmente a segurança jurídica tanto dos consumidores como das empresas, que passarão a poder contar com um quadro jurídico único, baseado em noções jurídicas claramente definidas destinadas a regular certos aspectos inerentes aos contratos celebrados na Comunidade, entre as empresas e os consumidores“.

Parece, pois, evidente que a Comissão pretendia pôr fim, como ela própria afirmava, à fragmentação verificada nos quadros reguladores, de forma a diminuir as divergências normativas e interpretativas verificadas nos diferentes ordenamentos jurídicos, que poderiam, em seu entender, configurar graves riscos de segurança para o consumidor e para as empresas ${ }^{10}$. E, além do mais, acreditava que, ao submeter os Estados-Membros a critérios máximos garantiria, indubitavelmente, uma maior protecção dos consumidores.

Embora legítimas e coerentes as razões apresentadas pela Comissão face à complexidade de questões com as quais o consumidor se depara hoje em dia, tais objectivos podem, em nosso entender ser alcançados sem a submissão incondicional ao princípio da harmonização máxima. A este respeito, Hans Micklitz refere que o verdadeiro problema é o de saber como definir os objectivo das regras de harmonização máxima ${ }^{11}$. Países como a Alemanha procederam à transposição das directivas que regulam matérias do Direito de Consumo, assentes em critérios mínimos de subordinação à ordem jurídica europeia, pelo que a imperatividade da sua aplicação poderá sem dúvida desvirtuar o sentido de algumas leis nacionais, desfragmentando-as. Donde, afigura-se-nos que o combate à desfragmentação intracomunitário poderá, afinal, custar uma desfragmentação intranacional do direito do consumidor.

Concordamos, por isso, com JAN SMIT, quando este afirma não ser através de uma harmonização máxima que se verificará uma verdadeira e eficaz protecção do consumidor, até porque o nível de protecção imposto poderá revelar-se demasiado baixo

even lead to parties not contracting at all." [...] "The primary motive is to avoid distortions of competition by unifying national markets for the sale of goods and the provision of services ".

${ }^{10}$ SMIT, Jan (2009:7) "The Commission believes that full harmonization will considerably increase legal certainty for both consumers and business".

${ }^{11}$ MICKLITZ, Hans (2009), The Targeted Full Harmonization Approach. Looking behind the curtain, in Geraint Howells Reiner Schulze 8eds.), Modernising and Harmonising Consumer Contract Law, Minique: Sellier European Law Publishers. "The true problem however is how to define the scope of fully harmonized rules? [...]". 
para alguns países que desenvolveram o direito do consumo de forma mais alargada, no pressuposto do princípio da harmonização mínima ${ }^{12}$.

A tenção não existe apenas entre o direito europeu e os direitos nacionais de defesa do consumidor. Ela é visível, como se referiu anteriormente, no próprio quadro institucional europeu, onde à intenção confirmada da Comissão Europeia de fazer avançar a política e o direito dos consumidores em moldes mais liberais (de que a harmonização máxima é um dos seus instrumentos privilegiados) se opõem os dois principais comités consultivos (CESE e CReg) e o Parlamento Europeu.

A consulta aos pareceres do Comité Económico e Social Europeu (CESE) ${ }^{13}$ e do Comité das Regiões (CReg) ${ }^{14}$ deixa perceber a discordância dos interesses sociais e regionais organizados quanto a uma abordagem maximalista da proteção dos consumidores por via europeia. O CESE defende uma harmonização plena somente para as questões relativas às vendas fora de estabelecimentos comerciais e às vendas à distância, rejeitando-a no que diz respeito às cláusulas abusivas e às garantias nas vendas. Por sua vez, o CReg refere a novidade que é a harmonização completa no direito europeu de defesa do consumidor, alegando que esta não é absolutamente necessária, e argumenta que a mesma deveria ser reservada a aspectos muito específicos do mercado interno e que a harmonização mínima deveria ser prevalecente.

Do mesmo passo, uma análise dos debates ocorridos no Parlamento Europeu (PE) mostra bem o descontentamento que boa parte dos eurodeputados nutria pela proposta inicial da Comissão e a sua adesão às alterações avançadas pela Comissão do Mercado Interno e da Protecção dos consumidores do $\mathrm{PE}^{15}$. No desenrolar do processo legislativo e das negociações interinstitucionais subjacentes à adopção do texto da directiva, o princípio da harmonização total acabou por ser configurado numa versão “compromissória". Na tabela seguinte é possível descortinar as modificações que o texto foi sofrendo desde a proposta inicial redigida pela Comissão em 2008, passado

\footnotetext{
12 SMIT, Jan (2009), Full Harmonization of Consumer Law? A Critique of the Draft Directive on Consumer Rights, European Review of Private Law, volume.18.

${ }^{13}$ Cfr. CESE INT/464, de 16 de Julho de 2009.

${ }^{14}$ Cfr. CReg 9/2009 (DEVE-IV-038) adoptado na 79ª reunião plenária de 21 e 22 de abril de 2009.

${ }^{15}$ Cfr. a súmula de diversas intervenções dos parlamentares europeus nos debates em torno da alteração apresentada pelo parlamento Europeu ao texto inicial da Comissão Europeia, disponível em http://www.europarl.europa.eu/sides/getDoc.do?type=CRE\&reference=20110323\&secondRef=ITEM020\&language=PT\&ring=A7-2011-0038. Cfr. também o relatório da responsabilidade do eurodeputado Andreas Schwab que consagra a posição adoptada pelo PE e que foi comunicada ao Conselho e à Comissão que, em geral, o adoptaram dando lugar assim ao texto final da proposta de directiva (http://www.europarl.europa.eu/sides/getDoc.do?pubRef=-//EP//NONSGML+REPORT+A7-20110038+0+DOC+PDF+V0//PT).
} 
pelas alterações aprovadas pelo PE na sequência do Relatório Schwab, em 2011, até ao texto final adoptado em 2011.

Art. $4^{0}$ - Harmonização

\begin{tabular}{|c|c|c|}
\hline $\begin{array}{c}\text { Versão inicial } \\
\text { proposta em } \\
2008 \text { (Comissão) }\end{array}$ & $\begin{array}{c}\text { Versão aprovada em } 2011 \text { pelo Parlamento } \\
\text { Europeu } \\
\text { (três redacções alternativas) }\end{array}$ & $\begin{array}{l}\text { Versão final da } \\
\text { directiva } \\
\text { 2011/83/UE }\end{array}$ \\
\hline $\begin{array}{l}\text { Os Estados-Membros } \\
\text { não podem manter } \\
\text { ou introduzir na sua } \\
\text { legislação nacional } \\
\text { disposições } \\
\text { contrárias às } \\
\text { previstas na presente } \\
\text { directiva, } \\
\text { nomeadamente } \\
\text { disposições mais ou } \\
\text { menos rigorosas, que } \\
\text { tenham por objectivo } \\
\text { garantir um nível de } \\
\text { defesa dos } \\
\text { consumidores } \\
\text { diferente. }\end{array}$ & 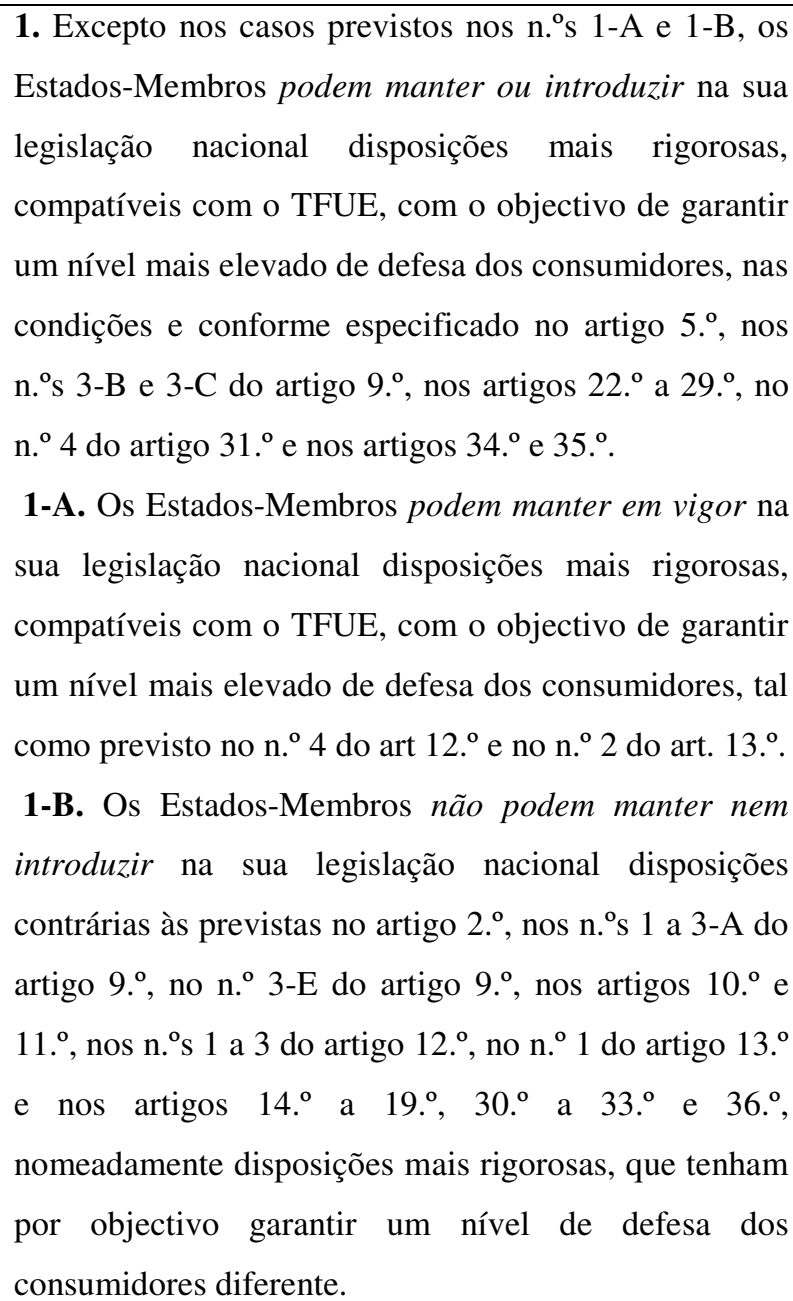 & $\begin{array}{l}\text { Os Estados-Membros } \\
\text { não devem manter ou } \\
\text { introduzir na sua } \\
\text { legislação nacional } \\
\text { disposições } \\
\text { divergentes das } \\
\text { previstas na presente } \\
\text { directiva, } \\
\text { nomeadamente } \\
\text { disposições mais ou } \\
\text { menos estritas, que } \\
\text { tenham por objectivo } \\
\text { garantir um nível } \\
\text { diferente de protecção } \\
\text { dos consumidores, } \\
\text { salvo disposição em } \\
\text { contrário na presente } \\
\text { directiva. }\end{array}$ \\
\hline
\end{tabular}

O texto de compromisso vertido na redacção final do art. $4^{\circ}$ (cuja epígrafe é Nível de harmonização) representa um pequeno passo atrás na intenção inicial da Comissão Europeia de promover uma harmonização completa (a própria epígrafe do artigo era sugestiva - Harmonização total), mas fica bastante longe das formulações propostas pelo Parlamento Europeu, que davam um espaço dominante à regra da harmonização mínima. Na verdade, os Estados-Membros acabam por só poder impor 
maiores exigências no que diz respeito a requisitos linguísticos e de informação (art. $6^{\circ}$, $\mathrm{n}^{\circ} 7$ e n. ${ }^{\circ} 8$ da directiva).

De seguida iremos apreciar o modo como o legislador português procedeu à transposição da directiva para a ordem jurídica interna. Especial ênfase será colocada nos aspectos que ofereciam espaço para um nível mais elevado de protecção por parte dos Estados-Membros e ao modo como eles foram abordados internamente.

\section{A transposição da Directiva 2011/83/CE para a ordem jurídica portuguesa}

\subsection{Os termos mitigados da harmonização máxima e a criatividade do legislador nacional}

As controvérsias e as oposições geradas em torno da harmonização máxima conduziram a uma redacção da directiva relativa aos direitos dos consumidores mais flexível em algumas (poucas) matérias, concedendo, assim, aos Estados-Membros espaços de criação reguladora.

De facto, a directiva prevê que os Estados-Membros possam desenvolver ou restringir o seu alcance em determinados aspectos. Entre eles poderemos indicar:

i) o âmbito da directiva ${ }^{16}$;

ii) os requisitos de informação aplicáveis a contratos diferentes dos contratos à distância ou dos contratos celebrados fora do estabelecimento comercial ${ }^{17}$;

iii) os requisitos linguísticos dos contratos celebrados à distância e dos contratos celebrados fora do estabelecimento comercial $^{18}$; i

v) os requisitos formais aplicáveis aos contratos celebrados fora do estabelecimento comercial ${ }^{19}$;

\footnotetext{
${ }^{16}$ Cfr. art. 3. ${ }^{\circ}$, n. 4 da Directiva 2011/83/EU, segundo o qual "os Estados-Membros podem decidir não aplicar a presente directiva nem manter ou introduzir disposições nacionais correspondentes para os contratos celebrados fora do estabelecimento comercial quando o pagamento a efectuar pelo consumidor não exceder 50 EUR. Os Estados-Membros podem definir um valor inferior na legislação nacional".

${ }^{17}$ Cfr. art. 5. ${ }^{\circ}$, n. $^{\text {o }} 4$ da Directiva 2011/83/UE: "Os Estados-Membros podem aprovar ou manter requisitos adicionais em matéria de informação pré-contratual para contratos a que se aplique o presente artigo."

${ }^{18}$ Cfr. art. 6. ${ }^{\circ}$, n. $^{\circ} 7$ da Directiva 2011/83/UE: "Os Estados-Membros podem manter ou introduzir no seu direito nacional requisitos linguísticos em matéria de informação contratual, de forma a assegurar que essa informação seja facilmente compreendida pelos consumidores".

${ }^{19}$ Art. 7. $^{\circ}$, n. ${ }^{\text {o }} 4$ da Directiva 2011/83/UE: "Nos contratos celebrados fora do estabelecimento comercial, em que o consumidor tenha solicitado expressamente os serviços do profissional para efectuar operações de reparação ou manutenção, e ao abrigo dos quais o profissional e o consumidor executam imediatamente as suas obrigações contratuais e o montante a pagar pelo consumidor não seja superior a 200 EUR: a) O profissional fornece ao consumidor as informações referidas no artigo $6 .^{\circ}$, n. ${ }^{\circ} 1$, alíneas b) e c), bem como informações sobre o preço ou a forma como este é calculado, juntamente com uma estimativa do preço total, em papel ou, se o consumidor concordar, noutro suporte duradouro. $\mathrm{O}$ profissional fornece as informações a que se refere o artigo $6^{\circ},{ }^{\circ} .^{\circ} 1$, alíneas a), h) e k), mas pode optar por não as fornecer em papel ou noutro suporte duradouro, se o consumidor der o seu acordo expresso; b)
} 
v) os requisitos formais aplicáveis aos contratos à distância naquilo que diz respeito à confirmação dos contratos ${ }^{20}$;

vi) a exigência de pagamento durante o período de retractação nos contratos celebrados fora do estabelecimento comercial ${ }^{21}$.

$\mathrm{Na}$ transposição efectuada pelo Decreto-Lei 24/2014, de 14 de Fevereiro, o legislador português aproveitou para desenvolver algumas destas matérias nas quais lhe era concedida tal liberdade ${ }^{22}$.

Assim, naquilo que respeita aos requisitos de forma, nos contratos celebrados fora do estabelecimento comercial, o art. $9^{\circ}$ do Decreto-Lei 24/2014, de 14 de Fevereiro, consagra a obrigatoriedade dos mesmos serem redigidos por escrito e em língua portuguesa, impondo assim obrigações não decorrentes da directiva, mas decorrentes da legislação nacional existente em matéria de defesa do consumidor, designadamente do art. $7^{\circ}{ }^{\circ}$ n. ${ }^{\circ} 3$ da Lei 24/96, de 31 de Julho (Lei de Defesa do Consumidor).

Quanto aos requisitos formais aplicáveis aos contratos à distância naquilo que concerne à sua confirmação consagra o art. 8. $^{\circ}$, n. ${ }^{\circ} 6$ da Directiva 2011/83/UE que "se um contrato à distância for celebrado por telefone, os Estados-Membros podem prever que o profissional tenha de confirmar a oferta ao consumidor, que só fica vinculado depois de ter assinado a oferta ou de ter enviado o seu consentimento por escrito. Os Estados-Membros podem igualmente exigir que essa confirmação seja efectuada num suporte duradouro".

Neste seguimento, o legislador português optou por conceder uma redacção diferente na transposição, conduzindo a interpretações confusas e pouco claras.

De acordo com o art. 6. ${ }^{\circ}$ do Decreto-Lei 24/2014, de 14 de Fevereiro "o fornecedor de bens ou prestador de serviços deve confirmar a celebração do contrato à

A confirmação do contrato, fornecida nos termos do n. 2 do presente artigo, contém as informações previstas no artigo $6 .^{\circ}, \mathrm{n} .^{\circ} 1$. Os Estados-Membros podem decidir não aplicar o presente número."

${ }^{20} \mathrm{Cfr}$. art. 8. $^{\circ}$, n. ${ }^{\circ} 6$ da Directiva 2011/83/UE: "Se um contrato à distância for celebrado por telefone, os Estados-Membros podem prever que o profissional tenha de confirmar a oferta ao consumidor, que só fica vinculado depois de ter assinado a oferta ou de ter enviado o seu consentimento por escrito. Os Estados-Membros podem igualmente exigir que essa confirmação seja efectuada num suporte duradouro."

21 Cfr. art. 9. ${ }^{\circ}$, n. 3 da Directiva 2011/83/UE: "Os Estados-Membros não devem proibir as partes contratantes de cumprir as respectivas obrigações contratuais durante o prazo de retractação. Contudo, no caso dos contratos celebrados fora do estabelecimento comercial, os Estados-Membros podem manter a legislação nacional em vigor que proíba o profissional de exigir o pagamento ao consumidor durante um determinado período após a celebração do contrato."

${ }^{22}$ A directiva previa a sua transposição até 13 de Dezembro de 2013, estando os Estados-Membros obrigados a cumprir os seus dispositivos a partir de 13 de Junho de 2014. 
distância no prazo de cinco dias contados dessa celebração e, o mais tardar, no momento da entrega do bem ou antes do início da prestação do serviço”. Ora, para além de não especificar para que tipo de contratos tal confirmação é exigível, aplicando-se de uma forma genérica aos contratos celebrados à distância - que tanto podem ser realizados por telefone como através da internet - veio colocar algumas questões a nível legal de dificil interpretação.

A mera observação do preceito parece conduzir à interpretação de que o contrato só produzirá efeitos a partir do momento em que se verifique a referida confirmação ou seja que ela se revela um verdadeiro requisito essencial para a produção de efeitos do negócio juridico. O que para efeitos do direito de retractação que assiste ao consumidor, por via do art. $10 .^{\circ}$ do referido diploma, poderá conduzir a algumas questões práticas de dificil solução. Na verdade o preceito mencionado prevê que "o consumidor tem o direito de resolver o contrato [...] sem necessidade de indicar o motivo, no prazo de 14 dias a contar do dia da celebração do contrato, no caso dos contratos de prestação de serviços",23. Consideremos um contrato de prestação de um serviço de comunicações electrónicas de internet, televisão e telefone. Se A, consumidor celebrar um contrato no dia 1 de Junho de 2014, poderá exercer o seu direito de arrependimento até ao dia 14 de Junho ou até ao dia 19 do mesmo mês?

Parece-nos que, para uma maior protecção do consumidor, o mesmo só poderá efectivamente exercer o seu direito de arrependimento, quando estiver em condições de entender qual o alcance dado ao contrato. E de acordo com o art. ${ }^{\circ} 6^{\circ}{ }^{\circ}$ previamente analisado, parece-nos que o consumidor só poderá encontrar-se nessa posição quando lhe tiverem sido efectivamente concedidas todas as informações decorrentes do negócio celebrado, daí que o art. $6 .^{\circ}$, n. ${ }^{\circ} 2$ do referido diploma preveja que "a confirmação do contrato a que se refere o número anterior realiza -se com a entrega ao consumidor das informações pré -contratuais previstas no n. ${ }^{\circ} 1$ do artigo $4 .^{\circ}$, em suporte duradouro".

Já no que se refere à exigência de pagamento durante o período de retractação nos contratos celebrados fora do estabelecimento comercial e ainda que a Directiva tenha concedido ao legislador português a possibilidade de não prever essa obrigatoriedade, foi consagrada a obrigatoriedade de pagamento proporcional ao serviço

\footnotetext{
${ }^{23}$ Cfr. art. 10. ${ }^{\circ}$, n. ${ }^{\text {o }}$ 1, alínea a) do Decreto-Lei 24/2014, de 14 de Fevereiro "O consumidor tem o direito de resolver o contrato sem incorrer em quaisquer custos, para além dos estabelecidos no n. ${ }^{\text {o }} 3$ do artigo $12 .^{\circ}$ e no artigo $13 .^{\circ}$ quando for caso disso, e sem necessidade de indicar o motivo, no prazo de 14 dias a contar: $a$ ) Do dia da celebração do contrato, no caso dos contratos de prestação de serviços"
} 
prestado sempre que o consumidor requeira que este seja realizado durante o prazo de retractação, dos $14 \operatorname{dias}^{24}$.

\subsection{O direito à informação e o direito de arrependimento: avanços e recuos}

Realizada uma breve análise de algumas matérias nas quais o legislador português concedeu um maior enfoque, face às previsões dadas pelas Directiva, cumpre agora debruçar-nos sobre dois aspectos do Decreto-Lei 24/2014, de 14 de Fevereiro que a nosso ver merecem uma especial acuidade: o direito à informação e o direito de arrependimento.

De facto, ao longo dos tempos e da evolução legislativa relativa ao direito do consumo foi sendo criada a convicção de que o consumidor seria tanto mais protegido quanto mais informado se encontrasse. São vários os preceitos, dispersos pela legislação avulsa que o comprovam.

Assim, desde o regime jurídico das cláusulas contratuais gerais ${ }^{25}$ e da Lei de Defesa do Consumidor ${ }^{26}$, como bases paradigmáticas de regulação dos contratos de consumo, até à legislação sectorial, designadamente, a relativa ao crédito ao consumo ${ }^{27}$, serviços financeiros à distância ${ }^{28}$, aos serviços públicos essenciais ${ }^{29}$, aos contratos celebrados com agências de viagens ${ }^{30}$ têm vindo a ser reforçados os deveres de informação a serem prestados ao consumidor.

$\mathrm{O}$ mesmo ocorreu na regulação relativa aos contratos celebrados à distância e fora do estabelecimento comercial, já regulado pelo Decreto-Lei 143/2001, de 26 de Abril $^{31}$.

Contudo, por força da revogação do referido diploma, por via da transposição da Directiva 2011/83/UE, através do Decreto-Lei 24/2014, de 14 de Fevereiro, o legislador comunitário e português, conscientes de que a vulnerabilidade dos serviços prestados e dos bens fornecidos através daquelas vias exige uma informação mais detalhada e

\footnotetext{
${ }^{24}$ Cfr. art. 15. ${ }^{\circ}$, n. ${ }^{\circ} 2$ do Decreto-Lei 24/2014, de 14 de Fevereiro: "se o consumidor exercer o direito de livre resolução, após ter apresentado o pedido previsto no número anterior, deve ser pago ao prestador do serviço um montante proporcional ao que foi efetivamente prestado até ao momento da comunicação da resolução, em relação ao conjunto das prestações previstas no contrato".

${ }^{25}$ Cfr. arts. $.^{\circ},{ }^{\circ}{ }^{\circ}$ e $8 .^{\circ}$ do Decreto-Lei $446 / 85$, de 25 de Outubro

${ }^{26}$ Cfr. arts. 7. ${ }^{\circ}$ e $8 .^{\circ}$ da Lei $24 / 96$, de 31 de Julho

${ }^{27}$ Cfr. arts. 5. ${ }^{\circ}, 6^{\circ}$ e $8 .^{\circ}$ do Decreto-Lei $133 / 2009$, de 2 de Junho.

${ }^{28}$ Cfr. arts. 11. ${ }^{\circ}$ a $18 .^{\circ}$ do Decreto-Lei 95/2006, de 29 de Maio.

${ }^{29}$ Cfr. art. $4 .^{\circ}$ da Lei $12 / 2008$, de 26 de Fevereiro.

${ }^{30}$ Cfr. arts. 16. ${ }^{\circ}$ e $21 .^{\circ}$ do Decreto-Lei 199/2012, de 24 de Agosto

${ }^{31} \mathrm{Cfr}_{\text {arts. }}{ }^{\circ}$ 4. $^{\circ}$ e 5. ${ }^{\circ}$ do Decreto-Lei 143/2001, de 26 de Abril
} 
especifica a ser concedida ao consumidor, reforçaram os deveres de informação pré e contratual $^{32}$.

Entendemos, contudo, que um reforço no dever de informação e na aparente garantia de que ela foi bem prestada ao consumidor, com vista a coloca-lo numa posição de exercer uma opção económica racional e ponderada, não se revela suficiente para proteger o destinatário da prestação do serviço ou do fornecimento do bem.

Até, porque, são frequentes as disposições legislativas que presumem que o dever de informação foi cumprido quando o comerciante prova que procedeu à entrega ou à veiculação das informação consideradas essenciais ao regular cumprimento do contrato.

O próprio art. 6. ${ }^{\circ}$, n. 3 do Decreto-Lei 24/2014, de 14 de Fevereiro, sob análise no presente estudo, prevê que se encontra "dispensado do dever de confirmação do contrato o fornecedor de bens ou prestador de serviços que, antes da celebração do contrato, forneça ao consumidor as informações pré -contratuais em suporte duradouro $^{33}$.

Ora, é de comum conhecimento que as informações constantes dos contratos ou a informação pré-contratual incluída em suportes duradouros, para além de extensas, são tecnicamente complexas para o consumidor médio.

Em jeito de paralelismo poderemos, por exemplo, recorrer ao Relatório do Inquérito a Literacia Financeira da População Portuguesa realizado pelo Banco de Portugal aos consumidores, onde se concluiu que "as perguntas relativas à compreensão financeira procuraram avaliar directamente os conhecimentos dos indivíduos. Os resultados nesta área temática revelam deficiências de literacia financeira relacionadas com vários conceitos importantes para tomar decisões financeiras, o que também foi possível depreender da análise das áreas do questionário sobre atitudes e comportamentos 34,

Neste sentido, concordarmos com o Comité Economico Social e Europeu, no já referido parecer que emitiu relativo à Proposta de Directiva relativa aos Direitos dos Consumidores, segundo o qual "o consumidor europeu não pode ser visto

\footnotetext{
${ }^{32}$ Cfr. art. $4 .^{\circ}$ do Decreto-Lei 24/2014, de 14 de Fevereiro

${ }^{33}$ No mesmo sentido o art. 6. ${ }^{\circ}$, n. ${ }^{\circ} 5$ do Decreto-Lei 133/2009, de 2 de Junho que regula o regime jurídico do crédito ao consumo estipula que "considera -se que o credor cumpriu os requisitos de informação previstos no presente artigo e na legislação aplicável à contratação à distância de serviços financeiros se tiver fornecido a ficha sobre «Informação normalizada europeia em matéria de crédito a consumidores», devidamente preenchida.

${ }^{34}$ BANCO DE PORTUGAL (2010), Relatório do Inquérito à Literacia Financeira da População Portuguesa.
} 
exclusivamente numa óptica de mercado interno ou considerado como um agente racional no mercado, consciente e informado, que toma decisões numa pura lógica de concorrência, podendo a sua protecção resumir-se a uma maior e melhor informação".

Ana Maria Fonseca refere que "com o intuito de concretizar o conceito, e partindo da fórmula presente na directiva de que o consumidor médio é "normalmente informado e razoavelmente atento e advertido", identificámos diversos factores que nos levam à concretização deste consumidor ${ }^{35}$. Os critérios mais relevantes, em Portugal, são assim: a idade, a literacia, as condições socio-económico-culturais, o grau de atenção, a marca (abrangendo a publicidade, a embalagem e a qualidade do produto), e, por último, o conhecimento das práticas comerciais do sector".

De certo modo, poderemos concluir que o conceito de consumidor médio, para efeitos de determinar a diligência e o grau de rigor e racionalidade com que norteia as suas opções económicas, deverá ser analisado sob a égide de inúmeros factores, designadamente a idade, a literacia, as condições socio-económico-culturais, o grau de atenção, a marca (abrangendo a publicidade, a embalagem e a qualidade do produto), e, por último, o conhecimento das práticas comerciais do sector.

Pelo que, concluímos que a informação veiculada, de forma padronizada, sem atender ao tipo de destinatário que está em causa, não cumprirá com o objectivo primordial de maior protecção ao consumidor.

Ponderamos, assim, para a defesa de um dever de assistência nos contratos celebrados à distância ou fora do estabelecimento comercial, a par do que já se encontra regulado nos contratos de crédito ao consumo.

O art. 7. ${ }^{\circ}$ do Decreto-Lei 133/2009, de 2 de Junho, dispõe que "credor e, se for o caso, o mediador de crédito devem esclarecer de modo adequado o consumidor, por forma a colocá-lo em posição que lhe permita avaliar se o contrato de crédito proposto se adapta às suas necessidades e à sua situação financeira, cabendo -lhes, designadamente, fornecer as informações pré-contratuais [...] explicitar as características essenciais dos produtos propostos, bem como descrever os efeitos específicos deles decorrentes para o consumidor, incluindo as consequências da respectiva falta de pagamento".

\footnotetext{
${ }^{35}$ FONSECA, Ana Maria (2012), Do consumidor médio. Reflexões em torno do conceito, Tese de Mestrado, Universidade Católica da Portuguesa, Faculdade de Direito, Lisboa, disponível em http://repositorio.ucp.pt/bitstream/10400.14/10927/1/TESE_MariaAnaFonseca.pdf.
} 
A este respeito Gravato Morais refere que através deste imperativo "impõe-se ao credor [...] um dever de assistência (pré-contratual) ao consumidor revestido de larga amplitude: importa esclarecimentos esclarecimento adequados e uma avaliação da adaptação das particularidades do crédito ao perfil específico de um dado consumidor [...]. Com isto pretende-se obter uma clara, consciente e reflectida actuação do consumidor em vista da possível celebração do contrato de crédito"36

Através do dever de assistência o mutuante deverá, assim, não só informar consumidor mas avaliar se o produto vendido se adapta ao seu perfil, tendo em consideração as suas especiais características.

Questionamos, por isso, se a protecção do consumidor não seria melhor alcançada através da inclusão do mencionado dever de forma transversal a todas as relações jurídicas de consumo criadas, face à vulnerabilidade e assimetria posicional em que o mesmo se coloca naquilo que diz respeito às características dos produtos e serviços que contrata. E especialmente se não poderia vir a ser efectivamente aplicado e regulado nos contratos celebrados sem a presença física dos contraentes.

Por outro lado, o estudo da Directiva 2011/83/UE e do diploma que a transpôs ressalta uma matéria que nos parece de excepcional importância e que não poderá, por esse motivo, ser olvidada - o direito de retractação ou melhor de arrependimento.

Antes de mais, cumpre elaborar uma breve noção (ou distinção) do direito que está aqui em causa.

Carlos Ferreira de Almeida refere-se ao direito de arrependimento como compreendendo "todas as hipóteses em que a lei concede a um dos contraentes (o consumidor) a faculdade de, em prazo determinado e sem contrapartida, se desvincular de um contrato através de declaração unilateral e imotivada" ${ }^{, 37}$. Afasta-se por isso da figura da resolução contratual na medida em que esta deverá ter por base um motivo ou fundamento legal ou convencional ${ }^{38}$.

Em termos práticos, a figura do direito de arrependimento visa assegurar que $o$ consumidor avalie o serviço ou produto fornecidos, livre das pressões de marketing legitimamente exercidas e verifique racionalmente as suas reais característica com vista

\footnotetext{
36 MORAIS, Fernando de Gravato (2009), Crédito aos Consumidores, Anotação ao Decreto-Lei 133/2009. Coimbra: Almedina.

${ }^{37}$ ALMEIDA, Carlos Ferreira (2005), Direito do Consumo. Coimbra: Almedina.

${ }^{38} \mathrm{O}$ art. $432 .^{\circ}$, n. $^{\circ} 1$ do Código Civil assim o preceitua "é admitida a resolução do contrato fundada na lei ou em convenção."
} 
a garantir uma decisão racional e ponderada. Pelo que a nosso ver o mesmo deveria apresentar, na sua configuração jurídica, um elevado nível de protecção ao consumidor.

Ora, o Decreto-Lei 24/2014, de 14 de Fevereiro, manteve o prazo para o exercício do direito de arrependimento, alterando contudo o momento a partir do qual aquele deverá ser contabilizado.

Assim, nos termos do art. $10{ }^{\circ}$ do mencionado diploma "o consumidor tem o direito de resolver o contrato sem incorrer em quaisquer custos, para além dos estabelecidos no n. $^{\circ} 3$ do artigo $12 .^{\circ}$ e no artigo $13 .^{\circ}$ quando for caso disso, e sem necessidade de indicar o motivo, no prazo de 14 dias a contar: a) Do dia da celebração do contrato, no caso dos contratos de prestação de serviços; $b$ ) Do dia em que o consumidor ou um terceiro, com excepção do transportador, indicado pelo consumidor adquira a posse física dos bens, no caso dos contratos de compra e venda, ou: $i$ ) Do dia em que o consumidor ou um terceiro, com excepção do transportador, indicado pelo consumidor adquira a posse física do último bem, no caso de vários bens encomendados pelo consumidor numa única encomenda e entregues separadamente, ii) Do dia em que o consumidor ou um terceiro, com excepção do transportador, indicado pelo consumidor adquira a posse física do último lote ou elemento, no caso da entrega de um bem que consista em diversos lotes ou elementos, iii) Do dia em que o consumidor ou um terceiro por ele indicado, que não seja o transportador, adquira a posse física do primeiro bem, no caso dos contratos de entrega periódica de bens durante um determinado período; c) Do dia da celebração do contrato, no caso dos contratos de fornecimento de água, gás ou eletricidade, que não estejam à venda em volume ou quantidade limitados, de aquecimento urbano ou de conteúdos digitais que não sejam fornecidos num suporte material.”.

Deste modo e tal como referimos o prazo de 14 dias mantém-se, verificando-se ainda uma evolução da legislação no sentido de alargar o prazo 14 dias para 12 meses, no caso do fornecedor não cumprir com o dever de informar o consumidor do direito de livre resolução, tal como decorre do art. $4 .^{\circ}$, n. $^{\circ}$ 1, alínea j) do mesmo diploma (art. 10. $\left.\mathrm{n}^{\mathbf{o}} 2\right)^{39}$

Para além disso, o diploma agora vigente prevê uma forma mais célere do exercício deste direito, designadamente através do envio do modelo de «Livre

\footnotetext{
${ }^{39}$ Sem prejuízo de, no decurso desse prazo, o fornecedor de bens ou prestador de serviços cumprir o dever de informação pré -contratual a que se refere a alínea $j$ ) do $n .^{\circ} 1$ do artigo $4 .^{\circ}$, o consumidor dispor 14 dias para resolver o contrato a partir da data de receção dessa informação (art. $10^{\circ}$, n. $^{\circ} 3$ )
} 
resolução» constante da parte B do anexo ao decreto-lei 24/2014, de 14 de Fevereiro ou através de qualquer outra declaração inequívoca de resolução do contrato, considerando-se como tal a declaração em que o consumidor comunica, por palavras suas, a decisão de resolver o contrato designadamente por carta, por contacto telefónico, pela devolução do bem ou por outro meio susceptível de prova.

Assiste-se, contudo, a um retrocesso naquilo que diz respeito ao prazo a partir do qual deverá ser contabilizado o período para exercer o direito de arrependimento.

De facto, de acordo com o anterior regime - regulado pelo Decreto-Lei 143/2011, de 24 de Abril - o prazo de 14 dias, no que se referia à prestação de serviços seria contado a partir a partir do dia da celebração do contrato ou a partir do dia em que teria início a prestação ao consumidor, sempre que tenham sido cumpridas as obrigações referidas no artigo $5^{\circ}$ (relativas aos deveres de informação pré-contratual).

Da referida consagração resultava que o prazo de 14 dias para o exercício de direito de arrependimento apenas seria relevante a partir do momento em que fossem prestadas ao consumidor as informações pré-contratuais, consideradas essenciais ao abrigo do art. $5 .^{\circ}$ do mencionado diploma, o que na prática reconduzia a uma sua maior protecção, acautelando a possibilidade da cópia do contrato não lhe ser entregue.

Com a nova formulação o referido prazo conta-se a partir da celebração do contrato, ainda que este (ou as informações que dele decorrem) não seja entregue ao consumidor.

Para além disso e naquilo que aos efeitos do exercício do direito de arrependimento diz respeito, o art. $8 .^{\circ}, \mathrm{n}^{\circ}{ }^{\mathrm{a}} 1$ do anterior diploma previa que o fornecedor ficaria obrigado a reembolsar no prazo máximo de 30 dias os montantes pagos pelo consumidor, sem quaisquer despesas para este, salvo eventuais despesas directamente decorrentes da devolução do bem quando não reclamadas pelo consumidor.

Da redacção do novo diploma decorre uma formulação algo complexa e que pretendemos aqui esclarecer.

$\mathrm{O}$ art. $12 .^{\circ}$ do Decreto-Lei 24/2014, de 14 de Fevereiro dispõe que exercido o direito de arrependimento, o fornecedor de bens ou prestador de serviços deve reembolsar o consumidor de todos os pagamentos recebidos, incluindo os custos de entrega. Contudo e de forma algo paradoxal o art. $13 .^{\circ}$, n. $^{\circ} 2$ do mesmo diploma estipula que o consumidor apenas não suportará os custos de entrega do bem quando o fornecedor acordar em suportar esse custo ou quando o fornecedor não haja informado previamente o consumidor de que deverá suportar esses custos. Ora, considerando a 
hipótese de um consumidor celebrar um contrato de prestação de serviços, fora do estabelecimento comercial (e não à distância) sem que lhe tenha sido entregue cópia do contrato, o mesmo poderá apenas ter conhecimento desse facto, decorrido o prazo legalmente admitido para o exercício do direito de arrependimento, facto esse que poderia ter sido considerado essencial para a subscrição do contrato, por parte do consumidor.

Parece-nos que neste ponto especifico a revogação da anterior redacção do artigo acautelava em maior e melhor medida os interesses e direitos do consumidor.

Finalmente, a nova redacção do diploma abre a possibilidade de ser exigível, durante os primeiros 14 dias de contrato - ou seja durante o período necessário ao exercício do direito de arrependimento - o pagamento de um montante proporcional ao serviço prestado até à data de cancelamento ${ }^{40}$, sempre que o consumidor pretenda expressamente solicite que a prestação de serviço se inicie durante o referido prazo.

Ora, neste caso a lei permite que perante o exercício do direito de arrependimento por parte do consumidor, o prestador do serviço possa exigir o pagamento proporcional ao serviço prestado durante o período antes do cancelamento e neste caso o montante a ser cobrado terá por base o preço contratual total do contrato.

Perante esta situação apenas nos estranha a formula como será calculado este montante em contratos celebrados à distância mas que incluem um período de fidelização de 24 meses. Será esta cláusula de fidelização considerada para efeitos do preço contratual total? E, nesse caso, deverá o consumidor liquidar parte proporcional desse período de fidelização do qual poderá livremente se desonerar, volvidos 14 dias da celebração do contrato?

Ora, a resposta a estas questões ainda será muito embrionária face à entrada em vigor do diploma apenas no dia 13 de Junho de 2014, uma vez que só ai será possível analisar as práticas encetadas pelos operadores, na interpretação do diploma. De todo o modo parece-nos que, sem dúvida, embora o novo diploma tenha contribuído para alguns avanços na protecção do consumidor não clarificou algumas das questões essenciais à sua protecção económica, protecção essa que se encontra legalmente estipulada e tutelada pela LDC: "o consumidor tem direito à protecção dos seus interesses económicos, impondo-se nas relações jurídicas de consumo a igualdade

\footnotetext{
${ }^{40}$ Cfr. art. $15{ }^{\circ}$, n. ${ }^{\circ} 1$ do Decreto-Lei 24/2014, de 14 de Fevereiro.
} 
material dos intervenientes, a lealdade e a boa-fé, nos preliminares, na formação e ainda na vigência dos contratos"

\section{Conclusão}

O direito e a política dos consumidores têm vindo a sofrer uma alteração no paradigma que os tornara como preocupações transversais às demais políticas e à legislação europeias em matéria económica.

Uma abordagem de sentido mais liberal, protagonizada pela Comissão Europeia a partir do início deste século, subalternizou a defesa do consumidor aos ditames do mercado interno e reduziu a dinâmica de promoção dos seus interesses e da sua condição cidadã.

A directiva relativa aos direitos dos consumidores adoptada em 2001 e que cujo acto de transposição entrará em vigor na ordem jurídica nacional em junho deste ano, ilustra com clareza este novo posicionamento do executivo comunitário no domínio dos consumidores, ao mesmo tempo que espelha as resistências oferecidas por outras instâncias europeias até ao compromisso final.

E o processo de transposição, não obstante ter sido aproveitado em alguns aspectos para manter o nível de protecção mais elevado que já existia no direito português, não conseguiu evitar que em algumas áreas se verificasse um recuo legal que em nada beneficia os consumidores.

\footnotetext{
${ }^{41}$ Cfr. art. 9. ${ }^{\circ}$, n. ${ }^{\circ} 1$ da Lei 24/96, de 31 de Julho
} 